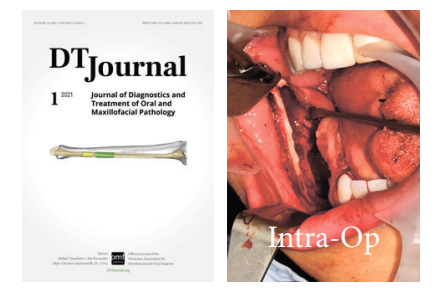

\title{
Laser CO2 to Decrease the Risk of the Recurrence in Odontogenic Myxoma When an Extensive Resection Is Not Possible
}

\author{
Andrés Pauwels-Tumiñana, Constanza Lozano-Morales ${ }^{b}$ Juan Pablo López, *, \& María Paula Orjuela ${ }^{d}$
}

\section{SUMMARY}

Within the head and neck neoplasms, odontogenic myxoma is considered as a benign neoplasm that can present an aggressive behavior. It is frequently associated with an important recurrence rate that is possibly related to incomplete resection. Among the most common surgical behaviors that can be followed to treat this lesion, we can find curettage or curettage with a peripheral osteotomy to reduce its recurrence rate. The use of a laser has been increasing, presenting good results in different procedures in the oral and maxillofacial region. The aim of this study is to propose an alternative treatment combining the use of the $\mathrm{CO} 2$ laser with the conventional curettage technique in order to reduce the risk of recurrence of the odontogenic myxoma and avoid invasive procedures that will affect the quality of life of the patient.

\footnotetext{
Bogotá, Colombia

a DDS, OMFS; Oral and Maxillofacial Surgeon, Head, Department of Oral Health Service, Hospital Universitario Fundación Santa Fe de Bogotá Professor, Universidad El Bosque.

${ }^{b}$ DDS, OMFS; Oral and Maxillofacial Surgeon, Chief, Division Oral and Maxillofacial Surgery, Hospital Universitario Fundación Santa Fe de Bogotá. Professor, Universidad El Bosque.

c DDS, Private Practice.

d DDS, Resident of Oral and Maxillofacial Surgery Program, Universidad El Bosque.

* Corresponding author's address: Private Practice, Bogotá, Colombia. Postal addresses 110111. Work telephone number: +57 (1) $6030303-$ ext. 5818, 5814, 5833.

E-mail: jplopez2304@gmail.com (Juan Pablo López)
}

E-mails of the co-authors:

ahapauwels@yahoo.ar (Andrés Pauwels-Tumiñan) lozanoconstanza@yahoo.com (Constanza Lozano-Morales) mapaula9413@gmail.com (María Paula Orjuela)

Please cite this article as: Pauwels-Tumiñan A, Lozano-Morales C, López JP, Orjuela MP. Laser $\mathrm{CO} 2$ to decrease the risk of the recurrence in odontogenic myxoma when an extensive resection is not possible. J Diagn Treat Oral Maxillofac Pathol 2021;5(1):3-9.

The abbreviation 'Intra-Op' at the upper right icon means that article contains intraoperative photographs.

Paper received 19 July 2020

Accepted 16 November 2020

Available online 29 January 2021

https://dx.doi.org/10.23999/j.dtomp.2021.1.2

(c) 2021 OMF Publishing, LLC. This is an open access article under the CC BY license (http://creativecommons.org/licenses/by-nc/4.0/). 


\section{INTRODUCTION}

Odenter dontogenic myxoma was first described by Thoma and Goldman in $1947 .{ }^{1}$ They reported eleven cases in the maxillary and jaw area, similar to those seen in long bones. In the oral cavity it may occur as a peripheral or central tumor with persistent pain. ${ }^{1}$ It is characterized by stellate and spindle-shaped cells dispersed in an abundant myxoid extracellular matrix. ${ }^{2}$ Its origin from ectomesenchymal cells and its frequency of appearance is 3 to 6 percent within all odontogenic tumors. ${ }^{3}$ The treatments reported for its management vary from curettage to block resection with safety margins. ${ }^{4}$ The latter mentioned is indicated because although this lesion is considered a benign neoplasm, it usually has an aggressive behavior due to it is infiltrative capacity. ${ }^{2}$ However, block resection treatments with wide margins can cause mutilation in the patient, which results in a decrease in self-esteem and quality of life and has a significant impact on the development of one person's healthy life. Therefore, the use of conservative techniques as an alternative to resection is discussed and defended, in order to mitigate the adverse results of these extensive procedures. Likewise, knowing the recurrence rate of these tumors makes it possible to consider complementing these conventional techniques with adjuvant therapies such as the use of $\mathrm{CO} 2$ lasers.

Laser therapy has been frequently used in oral cavity in recent decades due to the simplicity of its technique, limitation in bleeding, minimal pain and short surgical time. All these mentioned characteristics make it a tool with great advantages over other techniques. Therefore, its use has also increased in the field of oral surgery and some of the procedures where it is used include vascular lesions of the mucosa, over inserted oral structures, mucoceles and even in gingivitis, among others.

Therefore, the objective of this article is to suggest a combination of surgical techniques in the management of myxomas, including a conservative treatment and the additional use of the $\mathrm{CO} 2$ laser as an adjuvant therapy in order to reduce the likelihood of recurrence to the maximum.

\section{SURGICAL TECHNIQUE}

Having the patient under general anesthesia in a supine position, an incision and elevation of the flap is made according to what is indicated for the location of the myxoma. Then, an osteotomy is performed to expose the tumor with a piezoelectric device, removing the entire roof of the lesion. This maneuver is performed to avoid any remains of the tumor attached to the bone ceiling. Afterwards, a mechanical curettage of the lesion is developed (Fig 1 ), trying to maintain the integrity of the lesion so that it can be sent in one piece for histopathological analysis.

With previous osteoplasty with piezoelectric, a CO2 laser scan of the entire bone cavity and surrounding soft tissue is performed where friable debris of the tumor remain, which are difficult to remove due to their size and consistency. This debris can generate reappearance of the lesion, so vaporization is carried out with the laser configured in a continuous pulse at 5 watts (Fig 2). It is essential to protect the tissues that are not involved and follow all precautionary measures for the use of lasers in vital tissues. Finally, primary closure of the lesion is made and the follow-up visits for the patient are scheduled for the next eight days, one month, six months, one year, two years, three years and five years (Fig 3). Although a few cases have been made following this protocol, nowadays we have 4 cases of patients with a mean radiographic follow-up of five years. These cases have been successfully treated, with the absence of symptoms and radiographic changes that can suggest the recurrence of the lesion.

\section{DISCUSSION}

The odontogenic myxoma frequently presents multilocular characteristics with a bone expansion that invades it infiltrative. These characteristics make it aggressive and probably associated with the recurrence rate of the injury. Mechanical curettage, as the only treatment option, has a high recurrence rate. The recurrence rate varies within different studies, averaging 25 percent, but the prognosis remains good. Occasionally, extensive peripheral osteotomies are performed that may reduce the risk of recurrence, but this treatment tends to be mutilating. Additionally, this may be limited in large lesions and association with critical anatomical structures. ${ }^{2}$ The $\mathrm{CO} 2$ laser appears as an alternative to a block resection treatment for different benign or malignant lesions in different parts of the body. This laser was invented at Bell laboratories by Kumal Patel in $1964,{ }^{6}$ and since the '70s, it has been widely 


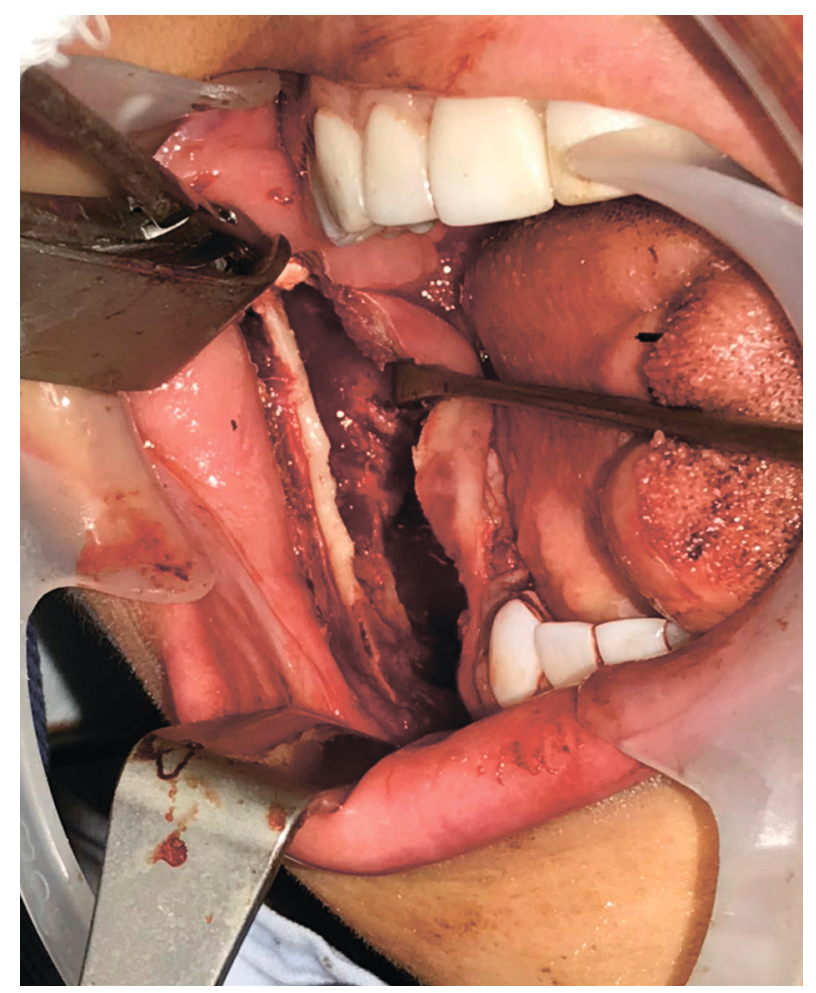

FIGURE 1. A bone cavity after mechanical curettage.

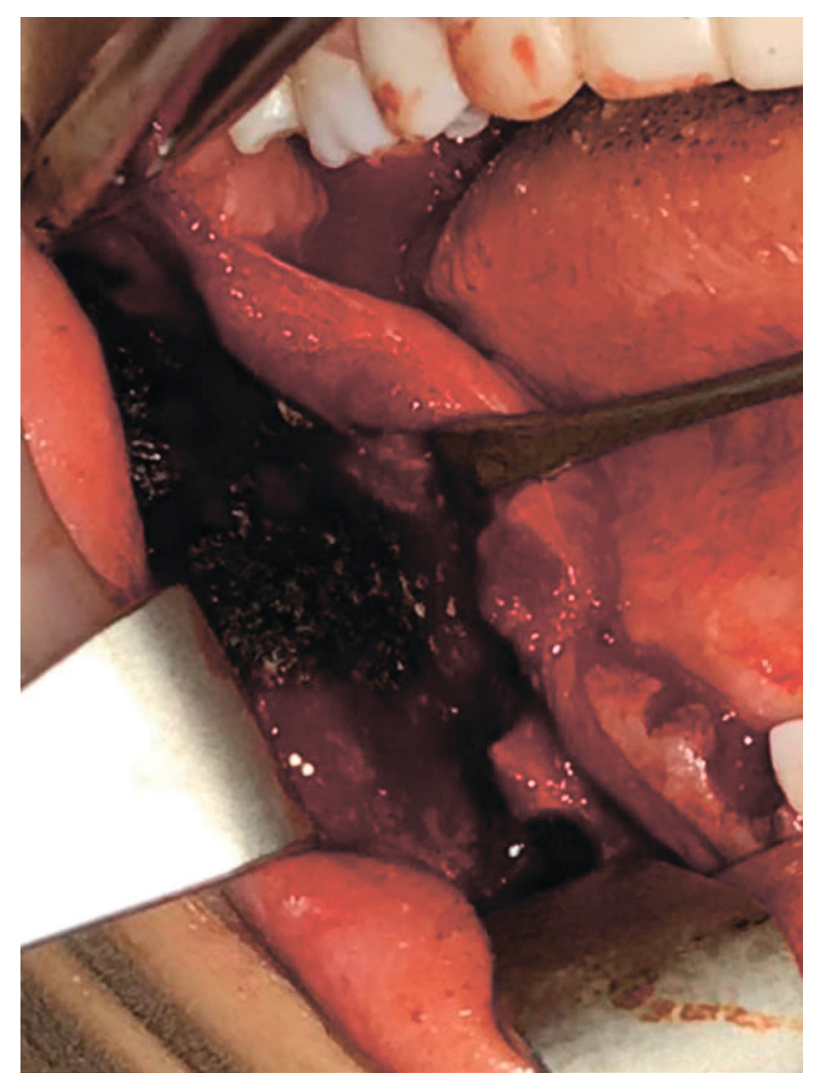

FIGURE 2. A bone cavity after the use of $\mathrm{CO} 2$ laser. 

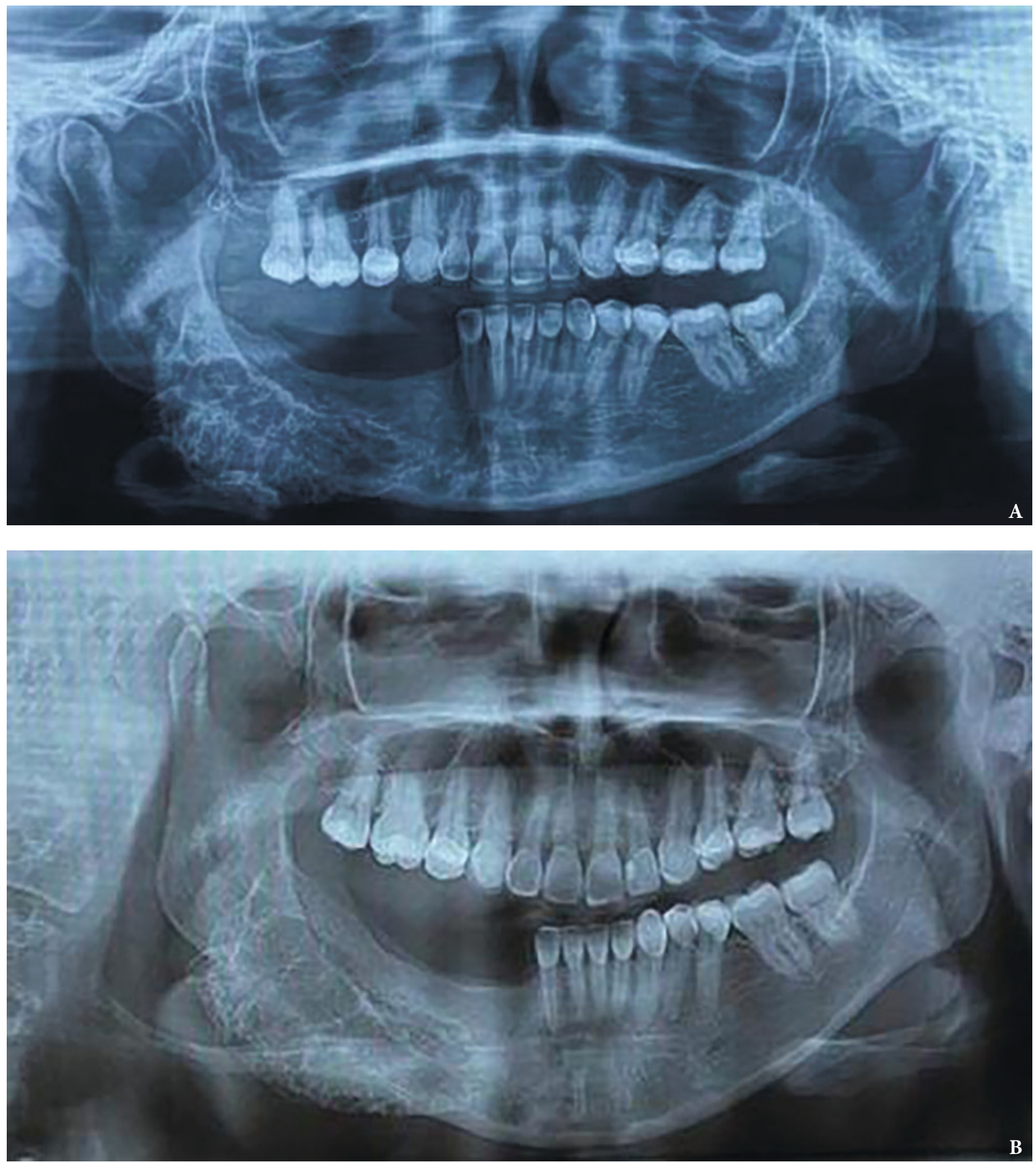

FIGURE 3. Orthpantomograms before (A) and after (B) surgery (five-year follow-up). 
used in the field of maxillofacial surgery, as well as in surgical procedures carried out in the oral cavity. ${ }^{7}$ This type of laser is part of the group of invisible rays included in the infrared wavelength $(10,600 \mathrm{~nm})$ and is classified within Low-Level Therapy (LLT) due to its therapeutic effect without the use of high temperatures. ${ }^{8}$ Its use in oral surgery is attributed to its great affinity for high water content tissues and many other advantages that make it stand out compared to the use of the cold scalpel. ${ }^{9}$ Its mechanism of action is based on the soft tissues absorbing energy in the form of heat produced by the laser, which causes evaporation of intra and extracellular fluid. This, in turn, causes cell disruption and loss of 75 to 95 percent of the cell volume represented in steam. All these effects occur at a temperature of $100^{\circ} \mathrm{C}$, but using higher temperatures, evaporation of the residual organic matrix can be achieved, resulting in total ablation of the soft tissue. ${ }^{10}$ This effect has been called photothermal effect and its consequences related to the collateral damage caused to cells on the periphery of the lesion, and the conservation of tissue that will be subjected to histopathological study have been extensively studied. Tuncer et $\mathrm{al},{ }^{11}$ in their study, show that the damages caused by the $\mathrm{CO} 2$ laser on the margins of the removed tissue, do not represent any inconvenience for the pathologist's diagnosis. However, this mentioned disadvantage does not affect the performance of the procedure that we propose in this article. In the technique that is developed, the removal of the tissue is performed initially with curettage, trying to preserve the intact specimen for analysis. On the contrary, this gives us an advantage because what we need is this evaporation of the possible debris of the lesion that may remain in the tissue after curettage.

Among the advantages related to its use mentioned in the literature, morphological and functional recovery in the postoperative period, pain control, minimization of surgical times, and reduction of the use of sutures or flaps can be highlighted. Besides, other high relevance qualities are reported, such as minimal damage to adjacent tissue and preservation of unaffected oral tissues, which in turn prevents the compromise of essential functions such as speech and swallowing. ${ }^{12}$ This last advantage plays a crucial role in surgical pathology, since, as previously mentioned, the procedures related to the treatment of benign lesions with aggressive behavior (such as myxoma) and malignant lesions, are usually extremely invasive. Also, the use of the $\mathrm{CO} 2$ laser allows the combination of other conventional techniques for tumor resection, such as curettage.

Regarding the reported disadvantages of laser methods in general, a delay in tissue healing is mentioned, mainly justified by the fact that, when intervening with these instruments, a rupture occurs in both blood vessels and lymphatic vessels, which leads to more time being consumed in the neovascularization process. ${ }^{10}$ However, this disadvantage is widely disputed because healing times have been well studied, and in some studies, a faster healing rate is suggested. In others, the results show a delayed healing rate, while in others, it is not found statistically significant differences. ${ }^{13}$ Lately, the laser has been recommended to treat benign oral lesions, such as fibromas, vascular anomalies, mucoceles, ranulae, gingival hyperplasias with different causes (idiopathic or due to side effects of medications), aphthous ulcers, mucosal frenula, or tongue ties (ankyloglossia), as well as premalignant lesions such as oral leukoplakia, erythroplakia, papillomas, and lichen planus. ${ }^{9}$ Furthermore, various authors have reported using this instrument for the resection of malignant tumors of the oral cavity. Wang et $\mathrm{al}^{14}$ in 2001 show favorable results, with a 5-year survival rate of 88 percent in patients with cancerous lesions of the anterior two-thirds of the tongue treated with a CO2 laser. In 2002, Ishii et a ${ }^{15}$ compared the use of $\mathrm{CO} 2$ laser with radiotherapy, showing statistically significant differences in metastasis in favor of patients treated with laser. Luna-Ortiz et al ${ }^{16}$ in 2019 studied the behavior of cancerous lesions in the oral cavity after their resection with $\mathrm{CO} 2$ laser, showing a survival rate of 60 percent with different follow-up times in each patient included in the study.

So far, no cases have been reported where the use of $\mathrm{CO} 2$ laser has been implemented for the treatment of oral myxoma. Therefore, a possible protocol is proposed, which can serve as a conservative therapeutic option in the future but without leaving aside the risk of recurrence. Hence, it is recommended to use $\mathrm{CO} 2$ laser vaporization in the surgical bed after the mechanical resection of lesions that, due to their consistency, can cause incomplete removal, increasing the risk of reappearance of these lesions, as in the case of myxomas. In any case, it is recommended to conduct further research with long-term follow-ups, hoping to obtain good results. On the other hand, it is essential to emphasize that with the use of any 
technique, it is crucial to carry out a periodic follow-up of the patient and even more in these cases that the use of conventional techniques is performed. Therefore, each patient's conditions must be taken into account, including their commitment to their general health, socioeconomic conditions, and ease and consistency in attending control appointments.

These aspects will play a vital role in choosing the best surgical technique that adapts to each patient's situation. Thus, in a patient with little commitment or whose conditions do not allow him to attend his controls regularly, the more invasive surgical procedures would be more indicated, since it is difficult to carry out an exhaustive control of the lesion's recurrence in this type of patient.

The age of the patient and other aspects must be considered, such as the relevance that the patient gives to his aesthetic condition. These aspects could lead us to take more conservative procedures into account with a higher priority. In this way, the treatment for each patient is individualized, and the best surgical technique is chosen according to their specific conditions.

On the other hand, although our experience has been limited and patient follow-up and data collection has been difficult, the results 5 years after the surgical procedure are very encouraging. These suggest that it may be a viable alternative for specific cases, making it clear that it is not the ideal treatment for odontogenic myxomas. The main limitation we had when it came to demonstrate the results was the limited information and the quality of the photos. However, we still believe that this alternative should be taken into account in the decision panel. It is also of great importance to continue monitoring patients and to consider other future publications that support or contradict the results.

\section{ROLE OF CO-AUTHORS}

Pauwels-Tumiñan A. (material processing).

Lozano-Morales C. (concept and design).

López J.P. (writing text, editing).

Orjuela M.P. (writing text, editing).

\section{FUNDING}

This research was funded through Hospital Universitario Fundación Santa Fe de Bogotá, Bogotá, Colombia.

\section{CONFLICT OF INTEREST}

The authors have expressed none conflict of interests.

\section{ETHICAL APPROVAL}

Not necessary.

\section{INFORMED CONSENT}

Informed consent was obtained from the patient.

\section{REFERENCES}

1. Thoma KH, Goldman HM. Central myxoma of the jaw. Oral Surg Oral Med Oral Pathol 1947;33(7):B53240. https://doi.org/10.1016/0096-6347(47)90315-3

2. Naggar AK, Chan JKC, Grandis JR, Takata T, Slootweg PJ. World Health Organization classification of head and neck tumours. 4th ed. Lyon: IARC Press. 2017.

3. Noffke CE, Raubenheimer EJ, Chabikuli NJ, Bouckaert MM. Odontogenic myxoma: review of the literature and report of 30 cases from South Africa. Oral Surg Oral Med Oral Pathol Oral Radiol Endod 2007;104(1):101-9. https://doi.org/10.1016/j. tripleo.2007.01.026

4. Boffano P, Gallesio C, Barreca A, Bianchi FA, GarzinoDemo P, Roccia F. Surgical treatment of odontogenic myxoma. J Craniofac Surg 2011;22(3):982-7. https:// doi.org/10.1097/SCS.0b013e3182101400

5. Khosraviani F, Ehsani S, Fathi M, Saberi-Demneh A. Therapeutic effect of laser on pediatric oral soft tissue problems: a systematic literature review. Lasers Med Sci 2019;34(9):1735-46. https://doi.org/10.1007/ s10103-019-02834-0

6. Patel CKN. Continuous-wave laser action on vibrational-rotational transitions of CO2. Phys Rev A 1964;136(5A):1187-93. https://doi.org/10.1103/ PhysRev.136.A1187

7. Jerjes W, Hamdoon Z, Hopper C. CO2 lasers in the management of potentially malignant and malignant oral disorders. Head Neck Oncol 2012;4:17. https:// doi.org/10.1186/1758-3284-4-17

8. Asnaashari M, Zadsirjan S. Application of laser in oral surgery. J Lasers Med Sci 2014;5(3):97-107.

9. Saibene AM, Rosso C, Castellarin P, Vultaggio F, Pipolo C, Maccari A, Ferrari D, Abati S, Felisati G. Managing benign and malignant oral lesions with carbon dioxide laser: indications, techniques, and outcomes for outpatient surgery. Surg J (N Y) 2019;5(3):e69e75. https://doi.org/10.1055/s-0039-1694735 
10. Strauss RA, Fallon SD. Lasers in contemporary oral and maxillofacial surgery. Dent Clin North Am 2004;48(4):861-88. https://doi.org/10.1016/j. cden.2004.06.005

11. Tuncer I, Ozçakir-Tomruk C, Sencift K, Cöloğlu S. Comparison of conventional surgery and $\mathrm{CO} 2$ laser on intraoral soft tissue pathologies and evaluation of the collateral thermal damage. Photomed Laser Surg 2010;28:75-9. https://doi.org/10.1089/pho.2008.2353

12. Roodenburg JLN, Witjes MJ, de Veld DC, Tan IB, Nauta JM. Lasers in dentistry 8. Use of lasers in oral and maxillofacial surgery (in Dutch). Ned Tijdschr Tandheelkd 2002;109(12):470-4.

13. Garg N, Verma S, Chadha M, Rastogi P. Use of carbon dioxide laser in oral soft tissue procedures.
Natl J Maxillofac Surg 2015;6(1):84-8. https://doi. org/10.4103/0975-5950.168218

14. Wang CP, ChangSY, WuJD, TaiSK.Carbondioxidelaser microsurgery for tongue cancer: surgical techniques and long-term results. J Otolaryngol 2001;30(1):1923. https://doi.org/10.2310/7070.2001.20897

15. Ishii J, Fujita K, Komori T. Clinical assessment of laser monotherapy for squamous cell carcinoma of the mobile tongue. J Clin Laser Med Surg 2002;20(2):5761. https://doi.org/10.1089/104454702753768025

16. Luna-Ortiz K, Hidalgo-Bahena SC, Muñoz-Gutiérrez TL, Mosqueda-Taylor A. Tumors of the oral cavity: CO2 laser management. Med Oral Patol Oral Cir Bucal 2019;24(1):e84-e88. https://doi.org/10.4317/ medoral.22811 